\title{
Stopping smoking and long-term mortality after acute myocardial infarction
}

\author{
JUKKA T SALONEN \\ From the North Karelia project, University of Kuopio and Epidemiological Research Unit of the Central \\ Public Health Laboratory of Finland, Kuopio, Finland
}

SUMMARY A prospective follow-up study was carried out to investigate the relation between smoking and risk of death after an acute myocardial infarction. The study consisted of male patients under the age of 65 years, who had had an acute myocardial infarction between 1972 and 1975 in North Karelia, Finland. Of these patients, 888 survived the first six months after the acute infarction and were followed-up for three years after the infarction with regard to their deaths. The cumulative all-causes mortality rate of the patients who were still smoking six months after the acute myocardial infarction was 1.7 times that of the patients who had stopped smoking within the first six months. There was a dose-response relation between the number of cigarettes smoked daily and the mortality. The impact of smoking was greatest in the subgroups of patients with an otherwise good prognosis. We estimated that 28 per cent of the deaths in the whole group of initial smokers was attributable to continuing smoking after the infarction. On the basis of these findings we suggest that anti-smoking advice should be an important part of the modern comprehensive care of patients with an acute myocardial infarction.

Some recent investigations show a lower mortality after an acute myocardial infarction in patients who stop smoking than in those who continue. ${ }^{1-3}$ There is also evidence that the lower mortality among the ex-smokers is not caused by other factors. In one earlier study the mortality in patients who stopped smoking did not differ from the mortality of those continuing smoking after infarction. ${ }^{4}$

On the basis of the above-mentioned two studies with positive results on the relation between smoking and the prognosis after a myocardial infarction, it has frequently been suggested that antismoking measures after a myocardial infarction should be given a high priority when implementing secondary preventive intervention.

The purpose of the present study was to compare the risk of death after acute myocardial infarction in smokers who continued smoking with those who stopped, independent of other factors related to the risk of death, in a representative group of male patients with acute myocardial infarction under the age of 65 , and in its risk-specific subgroups.

\section{Subjects and methods}

The study consisted of men under the age of 65 who were registered in the community myocardial Received for publication 13 August 1979 infarction register of North Karelia in Eastern Finland, which has some 180000 inhabitants. The registered heart attacks are classified as 'definite' or 'possible' acute myocardial infarction, no infarction, or 'insufficient information' according to the rigid operational criteria that were used in the international co-operative myocardial infarction register study co-ordinated by the WHO. ${ }^{56}$ The diagnostic criteria and the methods of data collection of the register have been published previously in detail. $^{\text {7-9 }}$ Only patients with a 'definite' or 'possible' acute myocardial infarction, who survived the first six months after the infarction, were included in the study.

Information concerning the deaths and the causes of death of the subjects during the three-year period after the infarction was collected from death certificates.

The data on smoking and medical history before the infarction were gathered in an interview by a nurse as early as possible after the acute phase of the attack. The data connected with the course of the acute period and the diagnostic criteria were collected using a standard questionnaire.

At six months and one year after the infarction, a postal inquiry was made in order to collect information about the health habits (for example, smoking) of the patients. 
The mortality from all causes between six months and three years after infarction of the patients who continued to smoke was compared with that of those who stopped smoking within six months of the infarction. The ratio of mortality of the smokers to that of the non-smokers was used as the statistic measuring the strength of the relation. Its variance and 95 per cent confidence limits were computed using the method concerning ratios of two proportions suggested by Thomas and Gart. ${ }^{10}$ The statistical significance of the overall rate ratios was based on the usual $x^{2}$ test of independence in a fourfold table, with Yates' correction for continuity. The results were considered statistically significant when the probability of type I error was less than 0.05 . The fraction of mortality attributable to smoking in the whole group was calculated as suggested by Levin. ${ }^{11}$ The variance and 95 per cent confidence interval of this statistic were computed as proposed by Walter. ${ }^{12}$

In order to control some of the expected covariates of smoking, we calculated mortality rate ratios after stratifying the material according to the covariates: age, history of previous myocardial infarction and angina pectoris, occurrence of acute heart failure or cardiac arrest, and a combined index of seven variables. The significance of stratumspecific rate ratios was tested using the Fischer exact test, with a doubled value of probability to get a two-tailed significance. When the smallest expected frequency exceeded 10 , the $x^{2}$ test with Yates' correction was used. In addition, a summary rate ratio was computed over the strata, in order to control for the confounding effect of some covariates, using the method of direct standardisation with the group of the non-exposed (non-smokers) as the standard as suggested by Miettinen. ${ }^{13}$ In computing the summary $x^{2}$ statistics, the Mantel-Haenszel procedure was applied. ${ }^{14}$

\section{Results}

There were 888 men registered in the North Karelia myocardial infarction register who passed the criteria for inclusion in the study. At interview after the infarction, 352 men reported not having smoked even one cigarette daily or the equivalent amount of other tobacco in the three months before the infarction; the information on previous smoking was missing in one patient. Two hundred and twenty-one men stopped smoking with in six months of the infarction, and 302 men reported in the postal interview that they still smoked six months after the infarction. For 19 patients, the data about smoking six months after infarction was missing. In seven of these, the data concerning the situation at 12 months was used. So there were 12 men $(1.3 \%)$ with no data on their smoking status at six and 12 months after infarction.

The number of deaths between six months and three years after infarction among the patients giving up and those continuing to smoke is presented in Table 1 according to the cause of death.

Of the initial non-smokers, 52 (14.8 per $100,95 \%$ confidence interval (CI) $11 \cdot 1$ to $18 \cdot 5)$ died between six months and three years after the infarction. Among those giving up smoking after the infarction the number of deaths was $26(11.8$ per 100, CI $95 \%$ $=7.5$ to 16.0 ). Of the patients continuing to smoke after infarction $60(19.9$ per 100, CI $95 \%=15.4$ to $24.4 \%$ ) died between six months and three years after infarction.

The estimated crude all-causes death rate among the patients continuing to smoke after the infarction was thus 1.7 times that of those who stopped smoking (CI $95 \%=1 \cdot 1$ to $\left.2 \cdot 6, x^{2}=5 \cdot 52, \mathrm{p}=0.019\right)$. The proportion of the deaths attributable to continuing smoking after infarction was 28 per cent (CI $95 \%=7$ to $50 \%$ ) or 24 (CI $95 \%=6$ to 43 )

Table 1 Deaths between six months and three years after acute myocardial infarction, according to smoking status and cause of death

\begin{tabular}{|c|c|c|c|c|c|}
\hline \multirow[t]{2}{*}{ Cause of death } & \multirow[t]{2}{*}{ Ex-smokers } & \multirow[t]{2}{*}{ Current smokers } & \multicolumn{2}{|c|}{ Rate ratio $\ddagger$} & \multirow{2}{*}{$\begin{array}{l}\text { Two-tailed } \\
\text { significance } \|\end{array}$} \\
\hline & & & $\begin{array}{l}\text { Point } \\
\text { estimate }\end{array}$ & CI $95 \% \S$ & \\
\hline $\begin{array}{l}\text { Ischaemic heart disease }{ }^{\star} \\
\text { Other cardiovascular disease } \dagger \\
\text { Other than cardiovascular disease } \\
\text { All deaths } \\
\text { Patients at risk }\end{array}$ & $\begin{array}{r}22 \\
2 \\
2 \\
26 \\
221\end{array}$ & $\begin{array}{r}49 \\
4 \\
7 \\
60 \\
302\end{array}$ & $\begin{array}{l}1.6 \\
1.5 \\
2.6 \\
1.7\end{array}$ & $\begin{array}{l}1 \cdot 0-2 \cdot 7 \\
0 \cdot 3-8 \cdot 0 \\
0 \cdot 5-12 \cdot 3 \\
1 \cdot 1-2 \cdot 6\end{array}$ & $\begin{array}{l}0.053 \\
0.995 \\
0.379 \\
0.019\end{array}$ \\
\hline
\end{tabular}

* Codes 410-414 according to the International Classification of Diseases (ICD), revision eight.

t ICD codes 390-404 and 420-458.

¥ When calculating the disease category specific mortality rates, the deaths in other diseases are included in the denominator.

$\S$ See text.

II See text. 
Table 2 Deaths from all causes between six months and three years after acute myocardial infarction, according to number of cigarettes smoked daily six months after infarction

\begin{tabular}{|c|c|c|c|c|c|}
\hline & \multirow{2}{*}{ Ex-smokers } & \multicolumn{4}{|c|}{ Current smokers } \\
\hline & & $1-4$ & $5-14$ & $\geqslant 15$ & All smokers \\
\hline $\begin{array}{l}\text { Deaths } \\
\text { Patients at risk } \\
\text { Mortality rate (\%) } \\
\text { CI } 95 \% \text { } \\
\text { Rate ratio† } \\
\text { CI } 95 \% \neq\end{array}$ & $\begin{array}{c}26 \\
221 \\
11 \cdot 8 \\
7 \cdot 5-16 \cdot 0\end{array}$ & $\begin{array}{c}9 \\
60 \\
15 \cdot 0 \\
6 \cdot 0-24 \cdot 0 \\
1 \cdot 3 \\
0 \cdot 6-2 \cdot 2\end{array}$ & $\begin{array}{c}33 \\
164 \\
20 \cdot 1 \\
14 \cdot 0-26 \cdot 3 \\
1 \cdot 7 \\
1 \cdot 1-2 \cdot 7\end{array}$ & $\begin{array}{c}18 \\
78 \\
23 \cdot 1 \\
13 \cdot 7-32 \cdot 4 \\
2 \cdot 0 \\
1 \cdot 1-3 \cdot 0\end{array}$ & $\begin{array}{c}60 \\
302 \\
19 \cdot 9 \\
15 \cdot 4-24 \cdot 4 \\
1 \cdot 7 \\
1 \cdot 1-2 \cdot 6\end{array}$ \\
\hline
\end{tabular}

$\star$ Calculated based on the assumption of binomial distribution.

+ Smokers in specific category of number of cigarettes smoked versus ex-smokers.

¥ See text.

out of the 86 deaths in the whole group.

When only the deaths between six and 12 months after the infarction are considered, the all-causes mortality rate ratio between smokers six months after the infarction and ex-smokers was $2 \cdot 4$ (CI $95 \%$ $=1.0$ to $\left.6.0, x^{2}=4.06, p=0.044\right)$. The respective rate ratio for deaths between six months and two years after the infarction was 2.0 (CI $95 \%=1.2$ to $\left.3 \cdot 4, x^{2}=6 \cdot 12, \mathrm{p}=0.013\right)$.

In the subgroup of patients with a 'definite' acute myocardial infarction the ratio of death rates between six months and three years comparing current smokers and ex-smokers was 1.7 (CI 95\%= $1 \cdot 1$ to $2 \cdot 7, x^{2}=4 \cdot 73, \mathrm{p}=0.030$ ).

In the whole group, 82.6 per cent of all deaths were the result of ischaemic heart disease. The smoking-related ischaemic heart disease mortality rate ratio of smokers to ex-smokers did not reach statistical significance $(p>0.05)$ and did not differ significantly from the respective all-causes mortality rate ratio. The relative mortality for all cardiovascular diseases was 1.6 (CI $95 \%=1.0$ to 2.6 ), and showed significance according to the test statistic $\left(x^{2}=4.03, p=0.045\right)$ (Table 1$)$. In order to study the existence of a dose-response relation between smoking and mortality after acute myocardial infarction, we examined the cumulative all-causes mortality from six months to three years after infarction at different levels of smoking (Table 2).

There was a trend for the rate ratio to increase with the number of cigarettes smoked daily.

In order to control the possible confounding effect of some factors expected to affect the mortality after acute myocardial infarction, all subjects were categorised first by age (Table 3) and, secondly, by history of previous acute myocardial infarction and/ or angina pectoris and occurrence of acute cardiac failure and/or cardiac arrest during the acute phase (Table 4).

While the total mortality after acute myocardial infarction increased slightly with age, the death ratio related to smoking after infarction did not show any consistent trend by age. There was no significant difference in the age distributions of exsmokers and current smokers. For this reason no age adjustment is included in the analysis of the

Table 3 Deaths from all causes between six months and three years after acute myocardial infarction, according to smoking status and age at onset of attack

\begin{tabular}{|c|c|c|c|c|c|c|}
\hline \multirow[t]{2}{*}{ Age (y) } & & \multirow[t]{2}{*}{ Ex-smokers } & \multirow[t]{2}{*}{ Current smokers } & \multicolumn{2}{|l|}{ Rate ratio } & \multirow{2}{*}{$\begin{array}{l}\text { Two-tailed } \\
\text { significance }\end{array}$} \\
\hline & & & & Point estimate & CI $95 \%$ & \\
\hline $28-44$ & $\begin{array}{l}\text { Deaths } \\
\text { Patients at risk }\end{array}$ & $\begin{array}{r}4 \\
37\end{array}$ & $\begin{array}{l}13 \\
61\end{array}$ & $2 \cdot 0$ & $0 \cdot 7-5 \cdot 9$ & 0.290 \\
\hline $45-54$ & $\begin{array}{l}\text { Deaths } \\
\text { Patients at risk }\end{array}$ & $\begin{array}{r}9 \\
94\end{array}$ & $\begin{array}{r}22 \\
111\end{array}$ & $2 \cdot 1$ & $1 \cdot 0-4 \cdot 4$ & 0.062 \\
\hline $55-64$ & $\begin{array}{l}\text { Deaths } \\
\text { Patients at risk }\end{array}$ & $\begin{array}{l}13 \\
90\end{array}$ & $\begin{array}{r}25 \\
130\end{array}$ & $1 \cdot 3$ & $0.7-2 \cdot 5$ & 0.458 \\
\hline & $\begin{array}{l}\text { Crude total } \\
\text { Deaths } \\
\text { Patients at risk } \\
\text { Adjusted summary }\end{array}$ & $\begin{array}{r}26 \\
221\end{array}$ & $\begin{array}{r}60 \\
302\end{array}$ & $\begin{array}{l}1 \cdot 7 \\
1 \cdot 7\end{array}$ & $1 \cdot 1-2 \cdot 6$ & $\begin{array}{l}0.019 \\
0.014\end{array}$ \\
\hline
\end{tabular}

* Computed using five-year age categories. 
Table 4 Deaths from all causes between six months and three years after acute myocardial infarction according to smoking status six months after infarction, history of previous infarction or angina pectoris, and occurrence of acute heart failure or cardiac arrest within first month after infarction

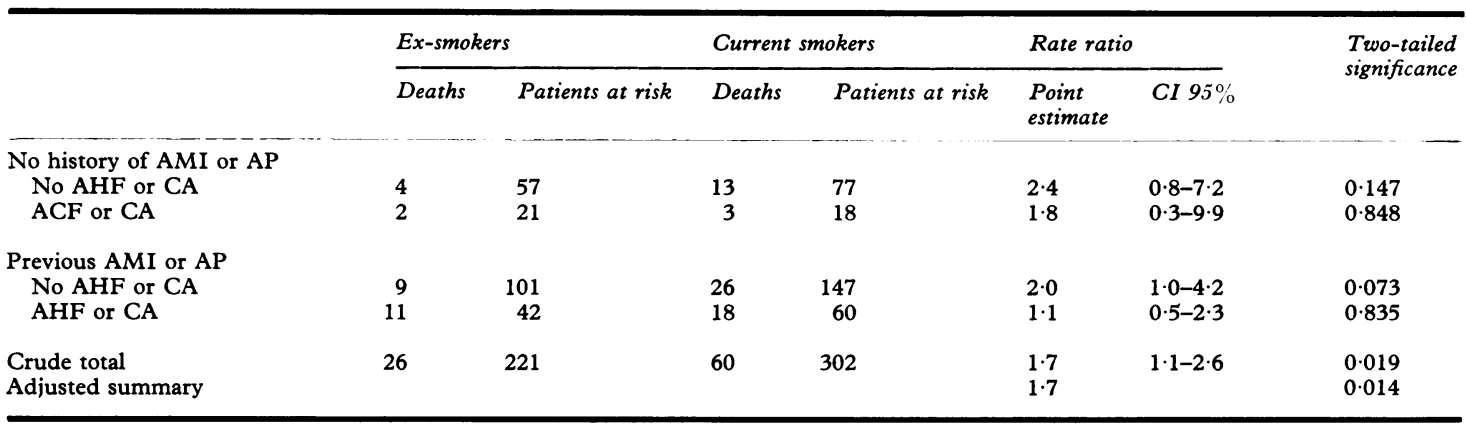

AMI, acute myocardial infarction; AP, angina pectoris; AHF, acute heart failure; CA, cardiac arrest.

importance of other possible confounding factors.

The smoking-related death rate ratio was insignificantly higher in the 'low-risk' subgroups, that is, in patients who had no other factors likely to contribute to high risk of death. Among patients without previous acute myocardial infarction or angina pectoris and without acute heart failure or cardiac arrest in the acute phase, the estimate of the rate ratio was 2.4 but did not deviate significantly from unity (Table 4). Previous acute myocardial infarction or angina pectoris was more prevalent among smokers than among non-smokers $(69 \%$ vs $65 \%)$. The smoking-related mortality rate ratio was also calculated according to the number of some selected factors contributing to mortality. These factors were age, diagnostic category of infarction, history of previous acute myocardial infarction, prodromal or previous angina pectoris, acute heart failure at the onset of attack, or during the hospital treatment, and cardiac arrest during the the hospital treatment (Table 5).

There was a slight downward trend in the smoking-related rate ratio with increasing number

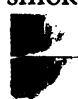

of other post-myocardial infarction risk factors (Table 5). The mortality of the smokers with not more than one of these risk factors was almost five times higher than that of the patients who stopped smoking. There were more smokers than exsmokers having at least four of the risk factors $(18 \%$ vs $11 \%$ ). The adjusted summary rate ratio calculated over the four strata was 1.6 and still statistically significant (Mantel-Haenszel $\chi^{2}$ with $1 \mathrm{df}=3.93$, $\mathrm{p}=0.035$ ).

\section{Discussion}

The purpose of the study was to investigate the relation between stopping smoking and long-term mortality after acute myocardial infarction, considering simultaneously some of the other factors contributing to this mortality and examining this relation in subgroups of patients with different risks of death.

For the study we chose all male patients under the age of 65 , who had suffered a definite or a possible acute myocardial infarction according to

Table 5 Deaths from all causes between six months and three years after acute myocardial infarction according to smoking status and number of selected factors related to risk of death

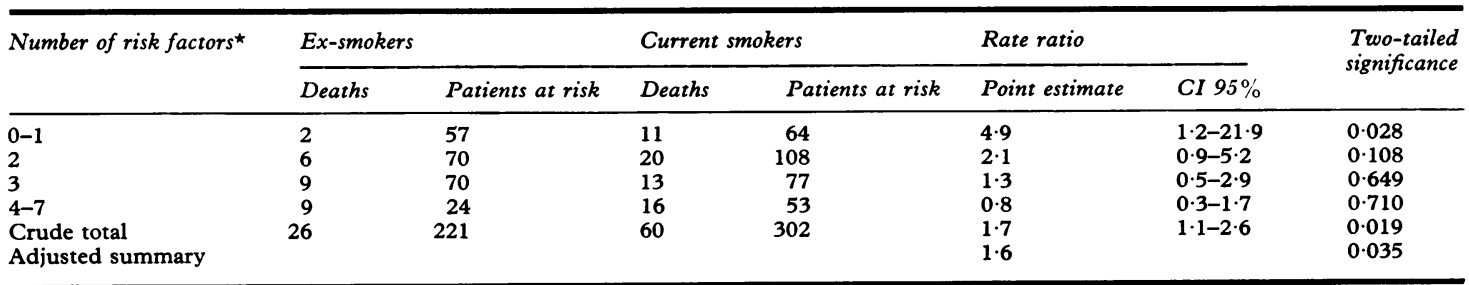

* The value of an additive index consisting of items age $(28-54=0,55-64=1)$; diagnostic category of infarction (possible $=0$, definite $=1)$; history of previous acute myocardial infarction $($ no $=0$, yes $=1$ ); prodromal or previous angina pectoris $($ not either $=0$, one or both $=1$ ); acute heart failure at onset of attack $($ no $=0$, yes $=1)$; acute heart failure during hospital treatment (no $=0$, yes $=1)$; cardiac arrest during hospital treatment $($ no $=0$, yes $=1$ ). 
the North Karelia community myocardial infarction register, and who had survived the first six months after the onset of symptoms.

The patients were from a complete unselected four-year series of men under 65 years of age with myocardial infarction who were detected in a geographically and administratively defined population. The diagnostic validity of the registration has been considered earlier, based on a blind reclassification into the defined diagnostic categories of a sample of the registered heart attacks. ${ }^{9}$ The coverage of the registration is being cross-checked against the national hospital discharge data.

The patients dying within the first six months after the infarction were not included in the study because the data concerning change in smoking habit were not available earlier than six months after the infarction. This resulted in a reduction of the study population but also decreased the possible confounding effect of infarct size and severity of infarction on the relation between smoking and mortality.

The data on smoking were almost complete though reliance had to be placed on a mailed questionnaire. The relation of smoking to mortality was studied solely on the basis of the deaths occurring after the measurement of smoking, and the smoking status during the follow-up of 'outcome events' (deaths) was not taken into account in the analysis, so that any bias caused by the selective missing data concerning smoking because of deaths could be avoided. It also follows, however, from the design that there might have been some 'drop-out' and 'drop-in' of smokers into the 'reference group', that is, ex-smokers and vice versa. It is likely that some smokers stopped smoking six months after the infarction, and some of those who had stopped smoking before six months started again afterwards. This assumption is supported by the finding that the mortality ratio between smokers and ex-smokers was higher when shorter periods of follow-up were considered. The contamination between the exposed and the nonexposed-the random error in the measurement of exposure-would have caused underestimation of the rate ratios.

The ratio of the mortality rate of smokers to that of ex-smokers was used as an estimator of relative risk, a measurement of the strength of the relation between smoking and survival. This was possible because of the prospective nature of the study. The use of the odds ratio (cross-product ratio) as an estimator of relative risk was considered improper because of the relatively high rate of outcome events, which exceeded the limit of 10 per cent that has been suggested as the maximum to make the approximation possible. ${ }^{15}$ The use of the odds ratio, as has been done in some studies with a similar design would probably have resulted in an overestimation of relative risks. In addition, the measure of statistical significance, $x^{2}$ with the correction for continuity, is a conservative test statistic and leads to two-sided testing of the relation studied.

It is possible that the design of the study and the statistical analysis of the data produce a bias towards accepting the null hypothesis rather than rejecting it. If smoking status after infarction had been defined in another way, its relation to mortality after infarction would probably have seemed closer.

Summary $x^{2}$ statistics were used as presented by Mantel and Haenszel, ${ }^{14}$ in which the weights for the strata of the covariate are given partly on the basis of their relative importance and partly to minimise the variance. According to the authors, the use of this summary statistic does not require the assumption of homogeneity of rate ratio over the strata to be combined. The use of the MantelHaenszel rate ratio statistic has been recommended as a combined estimator of the odds ratio, when the number of strata is more than two. ${ }^{16}$

In the whole group of initial smokers the total mortality between six months and three years after the infarction was 1.7 times and respective mortality from ischaemic heart disease was 1.6 times higher in the patients who continued to smoke than in those who gave up smoking within six months of infarction. The total mortality rate ratio was exactly the same in patients registered as having a definite acute myocardial infarction according to the defined rigid operational criteria.

It was found that the all-causes mortality in those giving up smoking was somewhat lower than that in initial non-smokers. This could be explained in two ways. Firstly, it is likely that initial smokers had a higher early mortality than non-smokers, as suggested by some previous studies. ${ }^{817}$ Therefore there might have been more patients with a severe course of infarction in the acute period who remained among the initial non-smokers. Secondly, those who did not smoke before the infarction must, on average, have had some factors other than smoking which increased the risk of infarction and probably also later the risk of death.

The strength of the relation between smoking and risk of death after acute myocardial infarction seemed to be increased in the subgroups of patients with a lower risk according to other factors contributing to post-myocardial infarction mortality. According to these data, the impact of smoking after acute myocardial infarction is almost twice as great among patients without a previous infarction or angina pectoris, and more than two-thirds greater 
among those without acute heart failure or cardiac arrest during the acute period of infarction, as compared with the others. The results of the analysis where seven important predictors of death after infarction were taken into account, also support the finding that continuing smoking after acute myocardial infarction is related to the greatest extra risk of death in the patients who otherwise would have had a good prognosis in terms of survival.

Among $\mathbf{4 0 5}$ male patients with a first myocardial infarction, aged 67 and below, who were registered in the Gothenburg myocardial infarction register, the patients who continued to smoke had a 1.9 times greater all-causes two-year mortality after infarction than those who had stopped smoking within three months of the infarction. ${ }^{1}$ In the series of 190 patients with a first attack of acute coronary insufficiency or myocardial infarction, aged under 60 , who were admitted to the cardiac department at St. Vincent's Hospital, Dublin, and who had survived 28 days or longer, the respective cumulative five-year mortality rate ratio was $1 \cdot 6$. The mortality of the patients who did not reduce their smoking (or did so by less than $50 \%$ ) was twice as high as those who stopped or reduced smoking by at least 50 per cent (calculated on the basis of the figures given in Table $3^{3}$ ). The strength of the relation in these two previous studies is of the same magnitude as that observed in the present study.

In the latter study, the relation of smoking to mortality after the infarction was also considered separately in the group of patients with acute coronary insufficiency or an 'uncomplicated' myocardial infarction and with a 'complicated' myocardial infarction. The rate ratios in these two subgroups between smokers and those who stopped or reduced were 1.4 and 4.0 (Table 4). ${ }^{3}$ Though not significant, this finding is not in agreement with the present study finding that smoking might have its greatest importance among patients with acute myocardial infarction without 'complications'. The lack of agreement could be caused by the small number of deaths in the Irish study, resulting in a large sampling variation, and by the difference in the selection of 'complications' that were taken into consideration.

In the present study there was a direct, statistically significant overall association between smoking and long-term prognosis after an acute myocardial infarction and a clear dose-response relation. In addition, the measurement of smoking preceded the observation of mortality, and the association remained significant, when the effect of some of the most important confounding factors was removed. So, assuming that there were no other extraneous factors producing a pseudoassociation, the association could be considered as a causal one, the mechanisms of which remain to be explained.

Because of the representativeness of the material the results seem to be applicable to any infarction patient population with similar characteristics. The existence of a common causal relation is supported by earlier similar findings. It is probable that the relation is strongest among patients with an otherwise good prognosis.

On the basis of our findings we estimated that among patients who had smoked before the infarction, 28 per cent, or 24 out of the 86 deaths, were attributable to continuing to smoke after the infarction and thus could, theoretically, have been prevented for three years at least by complete control of smoking after the infarction. For the reason that smoking seems to be one of the few things affecting the prognosis after an acute myocardial infarction which can be modified permanently and without any side effects, antismoking advice should be an essential part of the modern comprehensive care of these patients.

Our findings suggest that an individual patient who had smoked before the infarction could reduce his risk of dying during the next years by one-third by giving up smoking after the infarction. This information could be useful in motivating the patients with an acute myocardial infarction to stop smoking.

Because of the considerable prognostic impact of smoking, further studies on the methods of antismoking health education among the patients with an acute myocardial infarction are needed.

\section{References}

${ }^{1}$ Wilhelmsson D, Vedin JA, Elmfeldt D, Tibblin G, Wilhelmsen L. Smoking and myocardial infarction. Lancet 1975; 1: 415-20.

${ }^{2}$ Mulcahy R, Hickey N, Graham I, McKenzie G. Factors influencing long-term prognosis in male patients surviving a first coronary attack. Br Heart $\mathrm{F}$ 1975; 37: 158-65.

${ }^{3}$ Mulcahy R, Hickey N, Graham IM, MacAirt J. Factors affecting the 5 year survival rate of men following acute coronary heart disease. Am Heart $\mathcal{F}$ 1977; 93: 556-9.

${ }^{4}$ Gillman $H$, Colberg $K$. Untersuchungen über die Lebensphase nach überstandenem Herzinfarkt. Dtsch Med Wochenschr 1969; 94: 933-9.

${ }^{5}$ World Health Organisation. Regional Office for Europe. Ischaemic heart disease registers. Report of the Fifth Working Group. Copenhagen: the Organisation, 1971.

'World Health Organisation. Regional Office for Europe. Myocardial infarction community registers. 
Public Health in Europe, No. 5. Copenhagen: the Organization, 1976.

'Puska P, Mustaniemi H. Incidence and presentation of myocardial infarction in North Karelia, Finland. Acta Med Scand 1975; 197: 211-6.

${ }^{8}$ Salonen J, Puska P, Mustaniemi H, Mäki J. Sydäninfarktin varhaisvaiheen kuolevuuteen liittyvistä taustatekijöistä. (Factors related to short-term fatality after acute myocardial infarction.) In Finnish. Sosiaalilääketieteellinen aikakauslehti 1977; 14: 23-32.

'Salonen JT, Puska P, Mustaniemi H. Changes in morbidity and mortality during comprehensive community programme to control cardiovascular diseases from 1972-7 in North Karelia, Finland. $\mathrm{Br} \mathrm{Med} \mathcal{J}$ 1979; 2: 1178-83.

${ }^{10}$ Thomas DG, Gart JJ. A table of exact confidence limits for differences and ratios of two proportions and their odds ratio. $3 \mathrm{Am}$ Stat Assoc 1977; 72: 73-6.

${ }^{11}$ Levin ML. The occurrence of lung cancer in man. Acta Un Int Cancr 1953; 9: 531-41.

${ }^{12} \mathrm{Walter}$ SD. The estimation and interpretation of attributable risk in health research. Biometrics 1976; 32: 829-49.

${ }^{13}$ Miettinen OS. Standardization of risk ratios. $A m \mathcal{f}$ Epidemiol 1972; 96: 383-8.

${ }^{14}$ Mantel N, Haenszel W. Statistical aspects of the analysis of data from retrospective studies of disease. f Natl Cancer Inst 1959; 22: 719-48.

${ }^{15}$ Miettinen OS. Evaluation of cause-effect relationship in epidemiology. Draft manuscript for a book to be published by the WHO, 1972.

${ }^{16} \mathrm{McKinlay}$ SM. The effect of non zero second-order interaction on combined estimators of the odds ratio. Biometrika 1978; 65: 191-202.

${ }^{17}$ Romo M. Factors related to sudden death in acute ischaemic heart disease. A community study in Helsinki. Vammala: Academic Dissertation, 1972.

Requests for reprints to Dr Jukka $T$ Salonen, University of Kuopio, Box 40, 70101 Kuopio 10, SF-Finland. 